\title{
Explorando o Pensamento Computacional em Salas de Aulas de Ciências
}

\author{
Ruallyson Moura \\ Departamento de Computação \\ UFRPE / Recife-PE / Brasil \\ ruallysonfelype@gmail.com
}

\author{
Fernando Santos \\ Departamento de Computação \\ UFRPE / Recife-PE / Brasil \\ fernando.santosgomes@ufrpe.br
}

\author{
Adrielle Sousa \\ Departamento de Computação \\ UFRPE / Recife-PE / Brasil \\ adrielle.tsousa@gmail.com
}

\author{
José Alexandre da Silva \\ ETEPD / SEE \\ Recife-PE / Brasil \\ jas@etepd.com
}

\author{
Rozelma França \\ Departamento de Educação \\ UFRPE / Recife-PE / Brasil \\ rozelma.franca@ufrpe.br
}

O pensamento computacional tem sido considerado uma habilidade necessária a todos, independente de seus campos de estudo e atuação [1]. Dada a sua natureza interdisciplinar, têm surgido pesquisas que versam sobre a sua aplicação em diferentes disciplinas do currículo [2]. Avanços recentes em métodos analíticos e de computação criaram ferramentas poderosas para a compreensão de diversos fenômenos, como os naturais, a partir de sua modelagem e simulação [3].

Nesse cenário, práticas pedagógicas podem ser viabilizadas, possibilitando aos estudantes compreender o pensamento computacional a partir de sua aplicação em disciplinas curriculares. Partindo destas práticas surge este trabalho, que busca, a partir da atuação do PIBID Computação da UFRPE, promover tal habilidade a partir da identificação de problemáticas de aprendizagem nas disciplinas de Física e Química em uma escolar pública de ensino médio de Pernambuco.

Para compreender o contexto e sujeitos da pesquisa, o método etnográfico [4] foi empregado, de forma virtual devido à pandemia da COVID-19. Diferentes instrumentos foram usados para coleta de dados, a saber: mídias sociais da escola, PPP e questionário online para professores e estudantes visando melhor compreender seus perfis e necessidades. De forma complementar, entrevistas semiestruturadas foram realizadas. Neste projeto, o foco foi sobre os professores de Física e Química.

A partir da análise dos dados [5] foram identificadas dificuldades de aprendizagem mais recorrentes nas disciplinas de Química e Física em conteúdos como: "Titulação","Equilíbrio Químico", "Física Estática" e "Equilíbrio de Forças". Sendo assim, ações pedagógicas foram definidas visando apoiar essa problemática a partir do pensamento computacional. Especificamente, a partir do uso de simuladores como o Phet [6] e o RexLab [7], da construção e prototipação de artefatos eletrônicos utilizando o Tinkercad [8].

Fica permitido ao(s) autor(es) ou a terceiros a reprodução ou distribuição, em parte ou no todo, do material extraído dessa obra, de forma verbatim, adaptada ou remixada, bem como a criação ou produção a partir do conteúdo dessa obra, para fins não comerciais, desde que sejam atribuídos os devidos créditos à criação original, sob os termos da licença CC BY-NC 4.0.

EduComp'21, Abril 26-30, 2021, Jataí, Goiás, Brasil (On-line)

(C) $\square 2021$ Copyright mantido pelo(s) autor(es). Direitos de publicação licenciados à Sociedade Brasileira de Computação (SBC).
Além disso, pretende-se ensinar lógica de programação e a linguagem $\mathrm{C}$ para a construção de um projeto de geradores de energia verde (e.g. eólica e solar). Este projeto, por sua vez, irá explorar a robótica com arduíno, os conhecimentos estudados na utilização dos simuladores e as habilidades desenvolvidas na aplicação interdisciplinar do pensamento computacional.

Para a utilização das ferramentas apresentadas e a elaboração das atividades com projetos, devido à pandemia da COVID-19, será utilizado aulas remotas como canal de ensino. Portanto, durante o processo, os estudantes se envolverão nas atividades de simulação de fenômenos, modelagem de artefatos robóticos e sua prototipação e escrita de relatórios.

Almeja-se, com isso, que eles consigam situar conceitos e práticas de pensamento computacional na resolução de problemas das disciplinas em foco, como também apoiar sua compreensão de conteúdos abstratos, favorecendo a sua aprendizagem. Também, espera-se aperfeiçoar suas habilidades interpessoais, de comunicação, de lógica e outras providas pelo trabalho em equipe.

\section{AGRADECIMENTOS}

O presente trabalho foi realizado com apoio do Programa Institucional de Bolsa de Iniciação à Docência (PIBID) da Coordenação de Aperfeiçoamento de Pessoal de Nível Superior (CAPES) - Edital 02/2020.

\section{REFERÊNCIAS}

[1] WING, J. M. Computational thinking. Communications of the ACM, v. 49, n. 3 , p. 33-35, 2006.

[2] FRANÇA, R. S. de Uma abordagem pedagógica incorporada para o desenvolvimento do pensamento computacional no ensino fundamental. Tese (Doutorado) - Universidade Federal de Pernambuco. CIn, Ciência da Computação, Recife, 2020.

[3] WEINTROP, David et al. Defining computational thinking for mathematics and science classrooms. Journal of Science Education and Technology, v. 25, n. 1, p. 127-147, 2016

[4] CRESWELL, John W. Investigação Qualitativa e Projeto de Pesquisa: Escolhendo entre Cinco Abordagens. 3 ed. Porto Alegre: Penso, 2014.

[5] UFRPE (2021). Diagnose - PIBID/UFRPE - Edital Capes 02/2020 Licenciatura em Computação - Escola Técnica Estadual Porto Digital. Disponível em $<$ https://www.flipsnack.com/pibidlions/portf-lio-pibid-computa-o-ete-portodigital.html>. Acesso em 26 de fev. 2021.

[6] PHET. Disponível em < https://phet.colorado.edu/pt_BR/>. Acesso em $27 \mathrm{de} \mathrm{fev.}$ 2021.

[7] REXLAB. Disponível em <https://rexlab.ufsc.br/>.. . Acesso em 27 de fev. 2021 
EduComp'21, Abril 26-30, 2021, Jataí, Goiás, Brasil (On-line)

Moura et al.

[8] TINKERCARD. Disponível em <https://www.tinkercad.com/>.. . Acesso em 27 de março 2021. 